\title{
MANAJEMEN RISIKO MUTU GULA KRISTAL PUTIH DI PABRIK GULA PADJARAKAN KABUPATEN PROBOLINGGO
}

\author{
Yuli Wibowo ${ }^{1}$, Bambang Herry Purnomo ${ }^{1}$, Erin Nur Putriani ${ }^{1 *}$ \\ ${ }^{1}$ Jurusan Teknologi Industri Pertanian, Fakultas Teknologi Pertanian, Universitas Jember \\ Email: putriani.erin@gmail.com
}

\begin{abstract}
PG. Padjarakan is one of the state-owned sugar factory under PTPN XI. that exist in East Java. Currently, some companies engaged in the sugar industry are faced with the level of competition. This requires that the company is able to produce quality products and in accordance with market demand so that companies get the maximum profit. A company in doing the development can not be separated from the risks that may or will occur. The purpose of this research are to identify risks, analyze risk level and formulate risk control strategy at Sugar factory of Padjarakan. The research method used to analyze the magnitude of risk factor using fuzzy logic and control strategy using analytical hierarchy process. The results show that the risk factors that affect PG. Padjarakan include raw material risk, processing risk and human resource risk, based on the calculation that the risk of Raw Materials is high. While the results of the calculation of the risk of the Processing Process are in the medium category. The results of the risk calculation Processing Process are in the medium category. The results of the calculation of the risk value of Human Resources are in the high category. All aggregation values obtained from these three risks are included in the high risk category. For control strategies, the highest priority is Human Resource Training.
\end{abstract}

Keyword: Sugar Industry, Quality Risk, Raw Materials, Human Resources.

\section{PENDAHULUAN}

Indonesia sebagai negara agraris memiliki sumber daya alam yang beraneka ragam serta memiliki potensi pertanian. Potensi pertanian merupakan penyumbang pertumbuhan ekonomi terbesar di Indonesia, salah satunya peranan penting sektor pertanian yaitu pemenuhan kebutuhan pokok. Pemenuhan kebutuhan pokok ini salah satunya adalah produk gula kristal putih (GKP). Kriteria mutu GKP yang berlaku di Indonesia (SNI) saat ini pada dasarnya mengacu pada kriteria lama yang dikenal dengan SHS (Superieure Hoofd Suiker), yang perkembangannya kemudian mengalami modifikasi dan terakhir SNI 3140.3:2010 (Kuswurj, 2009).

PT Perkebunan Nusantara XI mengelola 16 Pabrik Gula di Provinsi Jawa Timur, salah satu Pabrik Gula yang dikelola oleh PTPN XI adalah PG.
Padjarakan. Produk gula yang dihasilkan PG. Padjarakan merupakan jenis Gula Kristal Putih (GKP 2). Berdasarkan standart kualitas dinyatakan oleh lembaga Badan Standarisasi Nasional Indonesia (BSNI) gula kristal masuk dalam kategori SNI 3140.3.2010 dengan parameter kualitas warna gula (ICUMSA) <300 IU, besar jenis butir (BJB) $<1.2 \mathrm{~mm}$ dan kadar air $0.1 \%$. Proses produksi GKP di PG. Padjarakan kadang-kadang masih berwarna putih kecoklatan serta belum mencapai kategori minimal warna gula (ICUMSA) <300 dan besar jenis butir (BJB) $>1.2 \mathrm{~mm}$.

Proses produksi yang dilakukan industri gula memiliki risiko-risiko. Industri gula pada saat ini dihadapkan masalah tingkat persaingan. Hal ini mengharuskan perusahaan mampu memproduksi produk yang berkualitas dan 
sesuai dengan SNI yang berlaku. Oleh karena itu, perlu adanya manajemen risiko yang baik sehingga dapat meminimalisir dan dapat mencegah risiko tersebut.

Said dan Intan, (2001) menyatakan bahwa dalam mengembangkan agroindustri terdapat risiko-risiko yang mungkin terjadi. Adanya potensi risiko maka perlu adanya manajemen risiko untuk mengurangi risiko tersebut. Manajemen risiko dilakukan untuk menganalisis serta mengendalikan risiko dalam kegiatan produksi gula kristal putih.

Kemudian tujuan yang ingin dicapai dari penelitian ini adalah untuk mengidentifikasi risiko-risiko pada Pabrik Gula Padjarakan, menganalisis tingkat risiko pada Pabrik Gula Padjarakan, merumuskan strategi pengendalian risiko pada Pabrik Gula Padjarakan.

\section{METODE}

\section{Alat dan Bahan}

Alat yang digunakan dalam penelitian adalah perangkat keras komputer, serta perangkat lunak utama dalam pengolahan data penelitian yaitu Microsoft Excel 2010, software Expert Choice 2011 dan software MatLab R2007b.

Bahan yang digunakan dalam penelitian ini adalah kuesioner pakar yaitu, kuesioner fuzzy, kuesioner bobot faktor, kuesioner penilaian rulebase, dan kuesioner AHP.

\section{Tempat dan Waktu Penelitian}

Penelitian ini dilakukan di Pabrik Gula Padjarakan Kabupaten Probolinggo.

Waktu penelitian dilakukan pada bulan April sampai Juni 2018.

\section{Tahapan Penelitian}

Tahapan penelitian dilakukan dalam empat tahapan penting yaitu :

1. Studi Pendahuluan

Pada tahapan ini dilakukan penelitian pendahuluan di Pabrik Gula Padjarakan yang mencakup observasi lapang, survei pakar dan studi pustaka.

\section{Identifikasi Permasalahan}

Tahapan ini dilakukan bertujuan untuk menemukan risiko-risiko yang dihadapi oleh Pabrik Gula Padjarakan bersama pakar melalui wawancara.

\section{Diagnosa Risiko}

Tahapan ini dilakukan untuk menilai risiko-risiko yang telah teridentifikasi menggunakan kuesioner fuzzy.

\section{Strategi Pengendalian Risiko}

Tahapan ini dilakukan untuk menentukan alternatif pilihan pengendalian risiko menggunakan kuesioner AHP. 


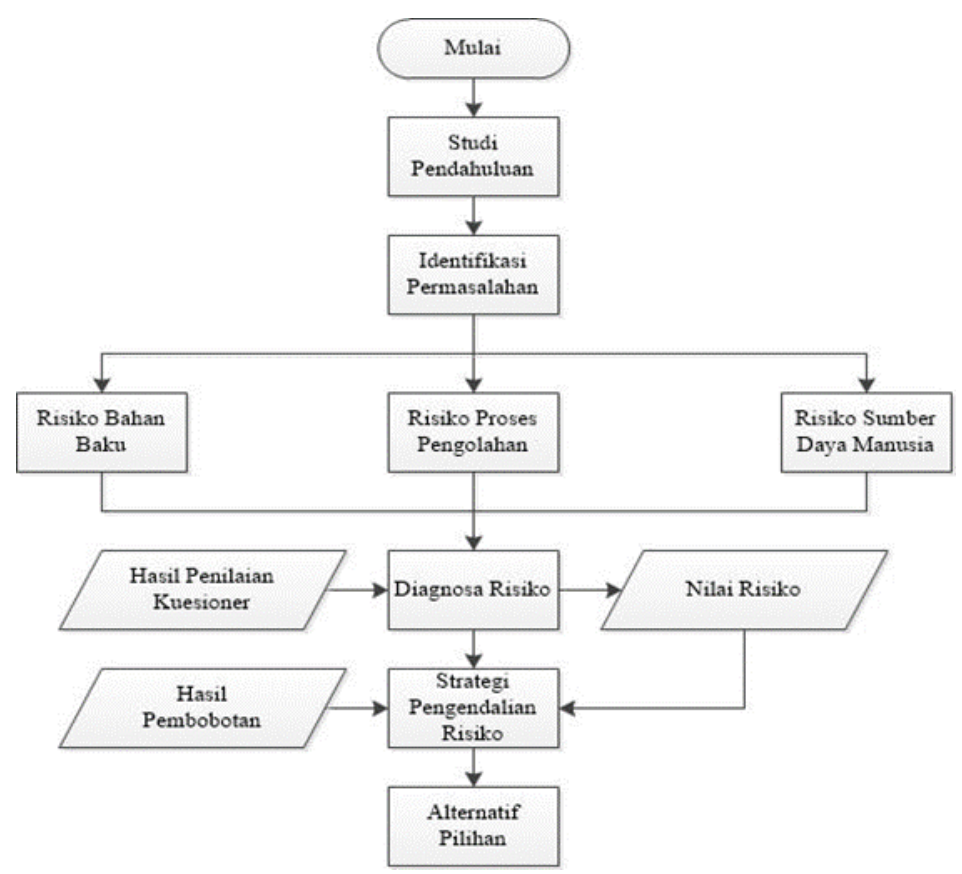

Gambar 1 Tahapan penelitian

\section{Metode Pengumpulan Data}

Data yang dikumpulkan terdiri dari data primer dan data sekunder. Data primer diperoleh dari observasi lapang, wawancara dengan pakar dan hasil kuesioner. Pakar penelitian terdiri dari 3 orang untuk masing-masing metode analisis yang terdiri dari Karyawan/Pekerja Pabrik Gula Padjarakan (5 orang) dan Dosen Fakultas Teknologi Pertanian (1 orang).

Data sekunder diperoleh dari studi pustaka meliputi data penunjang yang berkaitan dengan proses produksi Pabrik Gula Padjarakan. Data-data penunjang lainnya diperoleh dari jurnal online, skripsi peneliti lain dan sebagainya.

\section{Metode Pengolahan Data}

\section{Diagnosa Risiko}

Pada tahapan diagnosa risiko menggunakan metode logika fuzzy dan software yang membantu dalam proses perhitungan adalah MatLab R2007b. Adapun tahapan diagnosa risiko sebagai berikut :

a. Identifikasi Masalah
Identifikasi masalah bertujuan untuk mendapatkan faktor-faktor risiko yang terdapat pada Pabrik Gula Padjarakan. Berdasarkan hasil wawancara pakar, adapun indikator-indikator yang digunakan pada setiap risiko dapat dilihat pada Tabel 1.

Tabel 1 Indikator-indikator risiko

\begin{tabular}{llll}
\hline No & $\begin{array}{l}\text { Faktor } \\
\text { Risiko }\end{array}$ & \multicolumn{2}{l}{ Indikator } \\
\hline \multirow{2}{*}{ 1. } & Bahan & a. & Budidaya tanaman \\
& Baku & b. & Perawatan tanaman \\
& & d. & Jadwal tebang angkut \\
& & a. & Vacuum masakan \\
2. & Proses & b. & Vacuum penguapan \\
& Pengolahan & c. & Proses pemurnian \\
& & d. & Supplay uap \\
\hline & & a. & Jadwal \\
& Sumber & belatihan/training \\
3. & Daya & b. & Kejelihan \\
& Manusia & c. & indera \\
& & d. & Kontrol rutin \\
& & dotivasi kerja \\
\hline
\end{tabular}

Sumber: Data diolah (2018)

b. Penilaian

Penilaian masing-masing indikator menggunakan tiga skala, yaitu nilai 1 untuk 
"Rendah", 3 untuk "Sedang" dan 5 digunakan untuk "Tinggi". Penilaian fuzzy menggunakan pembobotan pada tiap-tiap input indikator risikonya. Bobot pada masing-masing indikator menggunakan skala 0-100. Jika dijumlah dalam setiap faktor risiko yaitu 100. Nilai label risiko dapat dilihat pada Tabel 2.

Tabel 2 Nilai label risiko

\begin{tabular}{cll}
\hline No & \multicolumn{1}{c}{ Variabel } & Nilai Label Risiko \\
\hline 1 & Output: & \\
& $\begin{array}{l}\text { Risiko industri } \\
\text { pabrik gula }\end{array}$ & Tinggi/Sedang/Rendah \\
\hline 2 & Input: & \\
& $\begin{array}{l}\text { a. Risiko bahan } \\
\text { baku }\end{array}$ & Tinggi/Sedang/Rendah \\
& b. Risiko proses & \\
& pengolahan & Tinggi/Sedang/Rendah \\
& c. Risiko & \\
& sumber daya & \\
& manusia & Tinggi/Sedang/Rendah \\
\hline
\end{tabular}

c. Pengembangan Aturan

Bentuk kaidah-kaidah mengolah data, dalam hal ini adalah tingkat risiko industri gula pasir menggunakan aturan if-Then atau metode rulebase. Salah satu contoh aturan (rulebase) dapat dilihat pada Tabel 3.

Tabel 3 Rulebase

\begin{tabular}{ccc}
\hline Aturan 1 & Parameter & Nilai \\
\hline IF & $\begin{array}{c}\text { Risiko bahan } \\
\text { baku }\end{array}$ & Rendah \\
\hline And & $\begin{array}{c}\text { Risiko proses } \\
\text { pengolahan }\end{array}$ & Rendah \\
\hline And & $\begin{array}{c}\text { Risiko sumber } \\
\text { daya manusia }\end{array}$ & Rendah \\
\hline THEN & $\begin{array}{c}\text { Risiko pada } \\
\text { industri rendah }\end{array}$ & \\
\hline
\end{tabular}

\section{d. Pengembangan Mesin Inferensi}

Mesin inferensi adalah komponen sistem pakar yang memanipulasi dan mengarahkan pengetahuan sehingga tercapai kesimpulan. Konfigurasi sistem fuzzy dapat dilihat pada Tabel 4.

Tabel 4 Konfigurasi sistem fuzzy

\begin{tabular}{lll}
\hline No. & Konfigurasi & Keterangan \\
\hline
\end{tabular}

\begin{tabular}{llc}
\hline 1. & Sistem fuzzy & Mamdani \\
2. & Metode AND & Minimum \\
3. & Metode OR & Maksimum \\
4. & Metode IMPLIKASI & Minimum \\
5. & Metode AGREGASI & Maksimum \\
6. & Metode DEFUZZIFIKASI & Centroid \\
7. & Fungsi keanggotaan & Bahu \\
\hline
\end{tabular}

\section{Strategi Pengendalian Risiko}

Strategi pengendalian risiko disusun berdasarkan skenario. Setelah dilakukan analisis risiko dengan menggunakan sistem pakar yang dibantu dengan sistem FIS (Fuzzy Inference System) diperoleh skenario.

Rumusan strategi pengendalian risiko menggunakan metode analytical hierarchy process (AHP). Adapun 4 prinsip dasar AHP sebagai berikut :

a. Penyususan Hierarki (Decomposition)

Struktur hierarki keputusan perumusan strategi pengendalian risiko mutu di Pabrik Gula Padjarakan terdiri dari 5 tingkatan level yaitu fokus/goal (level 1), faktor (level 2), aktor (level 3), tujuan (level 4), dan alternatif (level 5).

Fokus/goal (level 1) : Formulasi strategi pengendalian risiko mutu di Pabrik Gula Padjarakan

- Faktor (level 2) : Biaya (B), Kualitas Bahan Baku (KBB), Kualitas SDM (KSDM), dan Teknologi (T).

- Aktor (level 3) : Petani Supplier (PS), Manajer Perusahaan (MP), Pusat Pelatihan (PP), Pekerja (PK), dan Pemerintah (PM).

- Tujuan (level 4) : Kontinyuitas Produksi (KP), Mengurangi Risiko Cacat Produk (MRC), dan Meningkatkan Daya Saing Produk (MDS).

- Alternatif (level 5) : Melakukan Kontrol Kualitas (MKK), Memperbaiki Teknologi Proses yang Produktif dan Efisien (MTP), Mengembangkan Sistem Informasi Sumber Daya \& Operasi 
Perusahaan (MSI), dan Pelatihan Sumber Daya Manusia (PSDM).
b. Pengukuran
(Comparative Judgement)

Prinsip ini membuat penilaian tentang kepentingan relatif dua elemen pada suatu tingkat tertentu dalam kaitannya dengan tingkat di atasnya. Hasil penilaian disajikan dalam matriks perbandingan berpasangan (pairwise comparison). Adapun tabel skala dasar perbandingan dapat dilihat pada Tabel 5.

Tabel 5 Skala dasar perbandingan

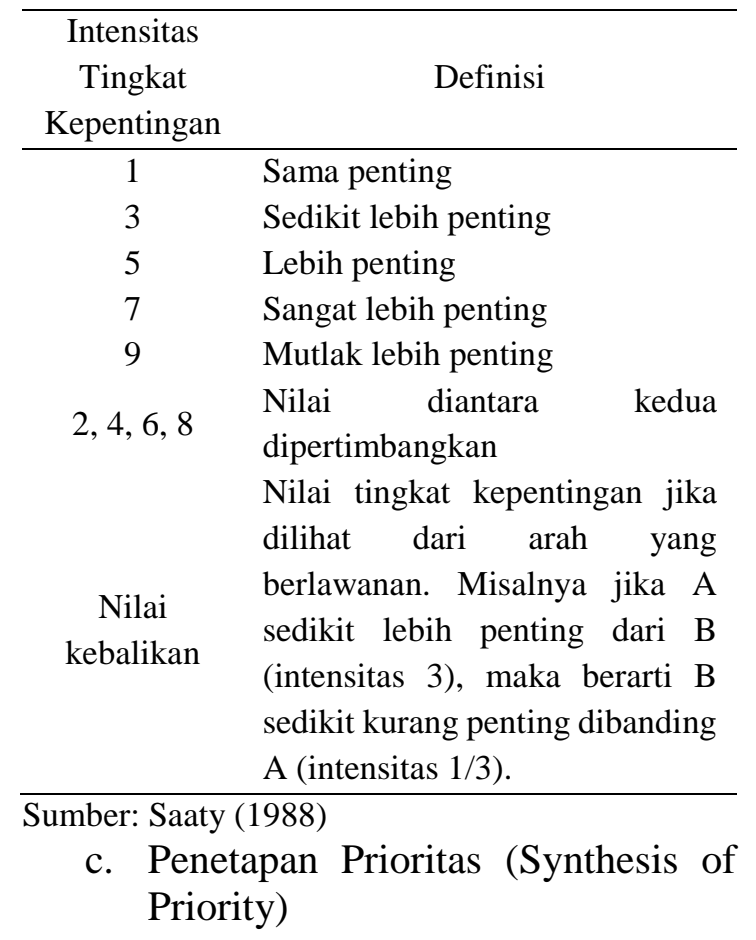

Pengolahan matriks pendapat terdiri dari dua tahap yaitu pengolahan horizontal dan pengolahan vertikal. Kedua jenis pengolahan tersebut dilakukan untuk Matriks Pendapat Individu (MPI) dan Matriks Pendapat Gabungan (MPG). Pengolahan vertikal dilakukan setelah MPI dan MPG diolah secara horizontal, dimana MPI dan MPG harus memenuhi persyaratan inkonsistensi.

Jika pakar yang digunakan lebih dari satu orang, maka pendapat dari masingmasing pakar perlu diagregasi terlebih dahulu membentuk MPG.

$$
g(i j)=\sqrt[m]{X_{k=1}^{m}}\left(a_{i j}\right) k
$$

Keterangan :

$\mathrm{g}(\mathrm{ij}) \quad=$ elemen MPG baris ke-i kolom ke-j

$\mathrm{m} \quad=$ jumlah pakar

(aij) $\mathrm{k}$ = elemen baris ke-i kolom ke-j dari MPI

ke-k

Pengolahan secara horizontal menunjukkan prioritas suatu elemen dalam satu tingkat terhadap elemen lain pada tingkat diatasnya. Terdiri dari tiga bagian yaitu penentuan vektor prioritas (vektor eigen), uji konsistensi, dan revisi MPI dan MPG yang memiliki rasio inkonsistensi tinggi. Rumus-rumus yang digunakan adalah :

- Perkalian baris (Zi),

$$
Z i=\sqrt[n]{\prod_{k=1} n a_{i j}}
$$

- Perhitungan vektor prioritas (VP) atau eigen vektor,

$$
V P=\frac{\sqrt[n]{\prod_{k=1} n a_{i j}}}{\sum_{i=1} n \sqrt[n]{\prod_{k=1} n a_{i j}}}
$$

- Perhitungan nilai eigen maksimum ( $\lambda \max )$,

$$
\begin{aligned}
> & V A=\left(a_{i j}\right) \times \mathrm{VP} ; \text { dengan } \\
& \mathrm{VA}=(\mathrm{Vai}) \\
> & V B=\frac{V A}{V P} ; \text { dengan } \mathrm{VB}= \\
& \left(V_{b i}\right) \\
\lambda \max = & \frac{1}{n} \sum_{i=k} V i ; \text { untuk in }
\end{aligned}
$$

Pengolahan vertikal menunjukkan prioritas setiap elemen terhadap elemen yang lainnya dalam satu tingkatan. Pengolahan vertikal dilakukan dengan menyusun prioritas pengaruh setiap unsur pada tingkat hierarki keputusan tertentu terhadap sasaran utama atau fokus. Bila Cvij didefenisikan sebagai nilai prioritas pengaruh unsur ke-j pada tingkat ke-i terhadap sasaran utama, maka : 


$$
C_{v i j}=\sum C_{h i j}(t ; i=1) x V W(t ; i-1)
$$

untuk $\mathrm{i}=1,2, \ldots \mathrm{dst}$

Keterangan :

C_hij $(\mathrm{t} ; \mathrm{i}=1)=$ nilai prioritas yang ke-i terhadap unsur ke-t pada tingkat diatasnya $(i=1)$, yang diperoleh dari hasil pengolahan horizontal.

$\mathrm{VW}(\mathrm{t} ; \mathrm{i}-1)=$ nilai prioritas pengaruh unsur ke-t pada tingkat ke (i-t) terhadap sasaran utama, yang diperoleh dari hasil pengolahan horizontal.

d. Konsistensi Logis (Logical Consistency)

Konsistensi logis, menjamin bahwa semua elemen dikelompokkan secara logis dan peringkatkan secara konsisten.

Perhitungan indeks inkonsistensi (CI),

$$
\mathrm{CI}=\frac{\lambda \max -n}{n-1}
$$

Perhitungan rasio inkonsistensi (CR),

$$
\mathrm{CR}=\frac{\mathrm{CI}}{\mathrm{RI}}
$$

RI merupakan indeks acak (random index) yang dikeluarkan oleh Oak Ridge Laboratory (Saaty, 1993) dari matriks yang berorde 1-10 dapat dilihat pada Tabel 6.

Tabel 6 Random consistency index (RI)

\begin{tabular}{cccc}
\hline $\mathrm{n}$ & $\mathrm{RI}$ & $\mathrm{n}$ & $\mathrm{RI}$ \\
\hline 1 & 0 & 6 & 1.252 \\
2 & 0 & 7 & 1.341 \\
3 & 0.525 & 8 & 1.404 \\
4 & 0.882 & 9 & 1.452 \\
5 & 1.115 & 10 & 1.484 \\
\hline
\end{tabular}

\section{HASIL DAN PEMBAHASAN}

\section{Analisis Risiko Mutu}

\section{Analisis Risiko Mutu Setiap Variabel}

a. Risiko bahan baku

Berdasarkan hasil penilaian pakar yang telah dilakukan, hasil penilaian risiko bahan baku yang diperoleh dapat dilihat pada Tabel 7.

Tabel 7 Penilaian risiko bahan baku

\begin{tabular}{lccc}
\hline \multicolumn{1}{c}{ Indikator } & Bobot & $\begin{array}{c}\text { Agregasi } \\
\text { Nilai }\end{array}$ & Indeks \\
\hline $\begin{array}{l}\text { Budidaya } \\
\text { tanaman }\end{array}$ & 18,33 & 4,16 & 76 \\
$\begin{array}{l}\text { Perawatan } \\
\text { tanaman }\end{array}$ & 18,33 & 3,51 & 64 \\
$\begin{array}{l}\text { Jadwal tebang } \\
\text { angkut }\end{array}$ & 23,34 & 4,16 & 97 \\
$\begin{array}{l}\text { Waktu tunggu } \\
\text { giling }\end{array}$ & 40,00 & 4,16 & 166 \\
\hline \multicolumn{1}{c}{ Total } & & & 404 \\
\hline
\end{tabular}

Sumber: Data diolah (2018)

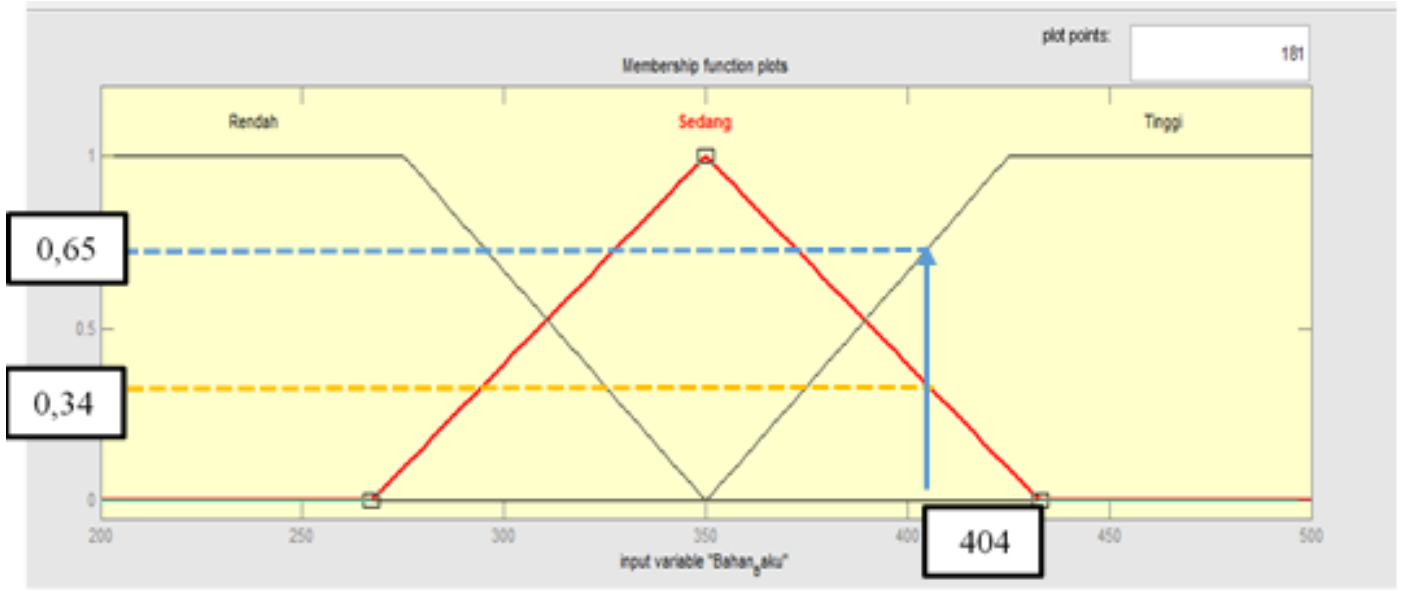

Gambar 2 Himpunan fuzzy pada variabel bahan baku

\section{Perhitungan Derajat Keanggotaan}

Nilai $x=(404)$

$\mu$ Rendah[404] $=0 ; x \geq 350$ $\mu$ Sedang $[404]=(433-x) /(433-350)$ $350 \leq x \leq 433$

$\mu$ Sedang $[404]=\frac{433-404}{433-350}=0.34$ 
> $\mu$ Tinggi $[404]=(\mathrm{x}-350) /(433-350)$;

$350 \leq x \leq 433$

$\mu$ Tinggi $[404]=\frac{404-350}{433-350}=0.65$

Berdasarkan penilaian pakar, hasil perhitungan yang diperoleh pada risiko bahan baku sebesar 404. Hal ini mengindikasikan bahwa risiko bahan baku pada PG. Padjarakan termasuk kategori risiko tinggi, dengan derajat keanggotaan $\mu$ Tinggi (0.65) dan $\mu$ Sedang (0.34). Nilai derajat keanggotaan yang diperoleh jika mendekati 1 maka mendekati kebenaran. Hal ini dapat terjadi karena, tebu yang ditebang dengan kurun waktu kurang dari 2 bulan. Hal ini berdasarkan kutipan Nita (2012) yang menyimpulkan, "Dalam merencanakan bahan baku tebu terlebih dahulu yang dilakukan oleh sinder kebun, setelah areal tanam diperoleh kemudian dilakukan analisis terkait produktivitas lahan. Setelah itu dilakukan pengolahan lahan, penanaman tanaman sampai tanaman tebu siap untuk ditebang. Sebelum dilakukan penebangan atau tebu dinyatakan siap untuk ditebang (masak optimal) 2 bulan sebelum tebu ditebang dilakukan analisis pendahuluan untuk mengetahui taksasi atau perkiraan nilai brix yaitu nilai yang menunjukkan tingkat kemasakan tebu.

b. Risiko proses pengolahan

Berdasarkan hasil penilaian pakar yang telah dilakukan, hasil penilaian risiko proses pengolahan yang diperoleh dapat dilihat pada Tabel 8.
Tabel 8 Penilaian risiko proses pengolahan

\begin{tabular}{llll}
\hline Indikator & Bobot & $\begin{array}{l}\text { Agregasi } \\
\text { Nilai }\end{array}$ & Indeks \\
\hline $\begin{array}{l}\text { Vacuum } \\
\text { masakan }\end{array}$ & 23.33 & 4.16 & 96.98 \\
$\begin{array}{l}\text { Vacuum } \\
\text { penguapan }\end{array}$ & 23.33 & 4.16 & 96.98 \\
$\begin{array}{l}\text { Proses } \\
\text { pemurnian }\end{array}$ & 26.67 & 4.16 & 110.86 \\
$\begin{array}{l}\text { Supply uap } \\
\text { Total }\end{array}$ & 26.67 & 2.89 & 77.15 \\
\hline
\end{tabular}

Sumber: Data diolah (2018)

\section{Perhitungan Derajat Keanggotaan}

Nilai $\mathbf{x}=(381.98)$

$>\mu$ Rendah $[381,98]=0 ; x \geq 350$

$>\mu$ Sedang $[381,98]=(433-x) /(433-350)$; $350 \leq x \leq 433$

$\mu$ Sedang $[381.98]=\frac{433-381.98}{433-350}=0.61$

$>\mu$ Tinggi $[381,98]=(\mathrm{x}-350) /(433-350) ;$ $350 \leq x \leq 433$

$\mu$ Tinggi381.98] $=\frac{381.98-350}{433-350}=0.38$

Berdasarkan penilaian pakar, hasil perhitungan yang diperoleh pada risiko proses pengolahan sebesar 381.98. Hal ini mengindikasikan bahwa risiko proses pengolahan pada PG. Padjarakan termasuk kategori risiko sedang, dengan derajat keanggotaan $\mu$ Tinggi (0.38) dan $\mu$ Sedang (0.61). Nilai derajat keanggotaan yang diperoleh jika mendekati 1 maka mendekati kebenaran.Hal ini dapat terjadi karena proses kristalisasi menggunakan pan masakan vacuum (hampa), sehingga tidak akan merusak gula yang dihasilkan. Pada saat proses penguapan, suhu yang digunakan terlalu tinggi terutama di badan 
pemanas (BP) akhir sehingga dapat merusak sukrosa pada nira. Pada proses pemurnian, pengaturan $\mathrm{pH}$, suhu dan waktu tinggal sesuai dengan SOP yang telah ditentukan sehingga kotoran mampu diendapkan secara maksimal. Supply uap ini berasal dari stasiun ketel (boiler), kemungkinan bahan bakar yang digunakan berkurang sehingga boiler tidak mampu menyuplai uap panas. Jika itu terjadi akan menghambat seluruh proses pengolahan.

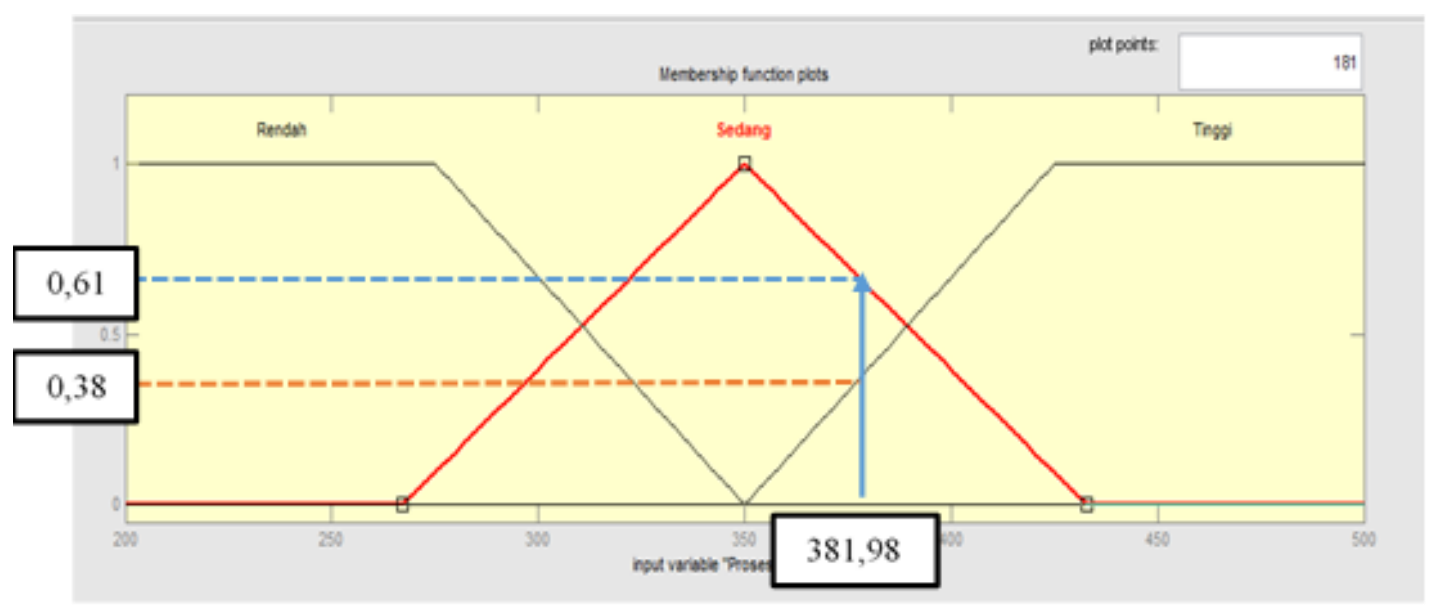

Gambar 3 Himpunan fuzzy pada variabel proses pengolahan

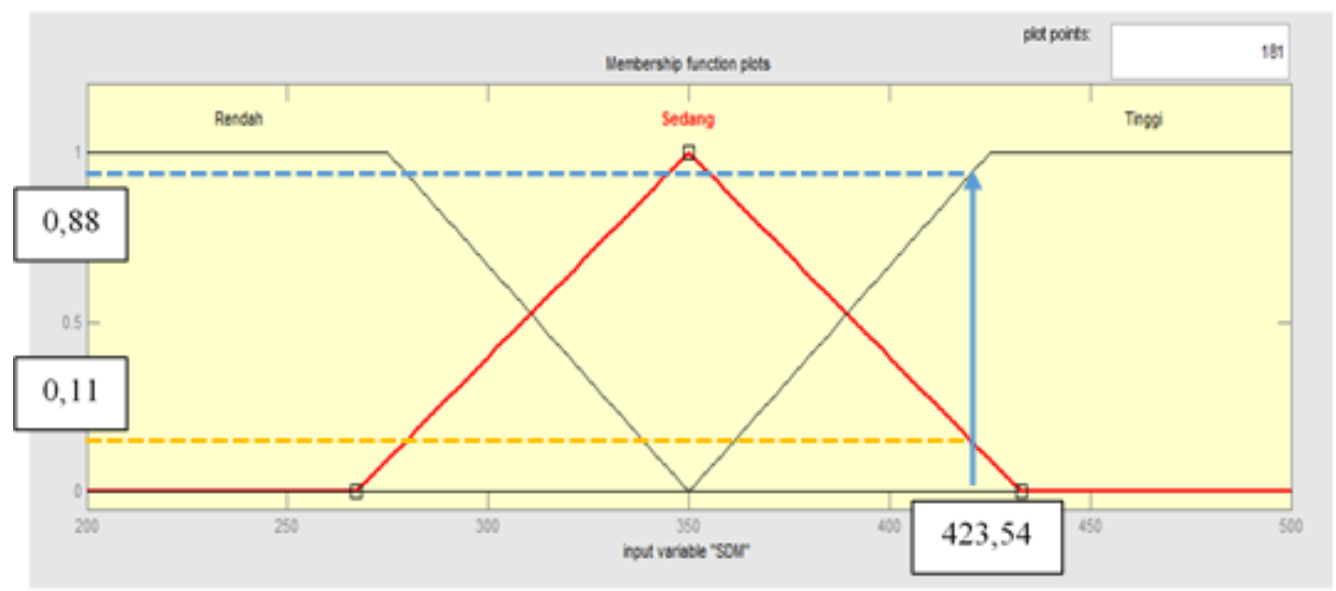

Gambar 4 Himpunan fuzzy pada variabel sumber daya manusia

c. Risiko sumber daya manusia

Berdasarkan hasil penilaian pakar yang telah dilakukan, hasil penilaian risiko sumber daya manusia yang diperoleh dapat dilihat pada Tabel 9.

Tabel 9 Penilaian risiko sumber daya manusia

\begin{tabular}{lccc}
\hline \multicolumn{1}{c}{ Indikator } & Bobot & $\begin{array}{c}\text { Agregasi } \\
\text { Nilai }\end{array}$ & Indeks \\
\hline Jadwal & 16.67 & 4.16 & 69.30 \\
pelatihan/training & & &
\end{tabular}

$\begin{array}{lccc}\text { Kejelihan panca } & 30.00 & 4.92 & 147.61 \\ \text { indera } & 30.00 & 4.16 & 124.71 \\ \text { Kontrol rutin } & 23.33 & 3.51 & 81.94 \\ \text { Motivasi kerja } & & & 423.54\end{array}$

Berdasarkan penilaian pakar, hasil perhitungan yang diperoleh pada risiko sumber daya manusia menunjukkan nilai 423.54. Hal ini mengindikasikan bahwa risiko sumber daya manusia pada PG. Padjarakan termasuk kategori risiko tinggi, dengan derajat keanggotaan $\mu$ Tinggi $(0,88)$ dan $\mu$ Sedang $(0,11)$. Nilai derajat 
keanggotaan yang diperoleh jika mendekati 1 maka mendekati kebenaran. Hal ini dapat terjadi karena jadwal pelatihan pekerja tidak rutin dilakukan, sehingga mengakibatkan pekerja kurang pengetahuan dan tidak begitu terlatih. Kejelihan panca indera pekerja kurang maksimal, kemungkinan karena faktor usia rentan 40-44, sehingga produk yang dihasilkan kurang maksimal. Dan untuk kontrol rutin peralatan kurang maksimal sebelum giling sehingga masih saja ada permasalahan yang dihadapi ketika giling berlangsung.

\section{Agregasi Variabel Risiko Mutu}

a. Aplikasi fungsi implikasi

Pada metode Mamdani, fungsi implikasi yang digunakan adalah harga min. Berikut ini merupakan hasil fungsi implikasi :

[R1] IF Risiko Bahan Baku SEDANG And Risiko Proses Pengolahan SEDANG And Risiko Sumber Daya Manusia SEDANG THEN tingkat risiko SEDANG

$\alpha$ Predikat $_{1}=\mu$ RBBSEDANG $\cap \mu$ RPPSEDANG $\cap$ $\mu$ RSDMSEDANG

$$
\begin{aligned}
& =\min [(0.34) ;(0.61) ;(0.11)] \\
& =0.11
\end{aligned}
$$

[R2] IF Risiko Bahan Baku SEDANG And Risiko Proses Pengolahan SEDANG And Risiko Sumber Daya Manusia TINGGI THEN tingkat risiko TINGGI

$\alpha$ Predikat $_{2}=\mu$ RBBSEDANG $\cap \mu$ RPPSEDANG $\cap$ $\mu$ RSDMTINGGI

$$
\begin{aligned}
& =\min [(0.34) ;(0.61) ;(0.88)] \\
& =0.34
\end{aligned}
$$

[R3] IF Risiko Bahan Baku SEDANG And Risiko Proses Pengolahan TINGGI And Risiko Sumber Daya Manusia SEDANG THEN tingkat risiko TINGGI

$\alpha$ Predikat $_{3}=\mu$ RBBSEDANG $\cap \mu$ RPPTINGGI $\cap$ $\mu$ RSDMSEDANG

$$
\begin{aligned}
& =\min [(0.34) ;(0.38) ;(0.11)] \\
& =0.11
\end{aligned}
$$

[R4] IF Risiko Bahan Baku SEDANG And Risiko Proses Pengolahan TINGGI And Risiko Sumber Daya Manusia TINGGI THEN tingkat risiko TINGGI

$\alpha$ Predikat $_{4}=\mu$ RBBSEDANG $\cap \mu$ RPPTINGGI $\cap$ $\mu$ RSDMTINGGI

$$
\begin{aligned}
& =\min [(0.34) ;(0.38) ;(0.88)] \\
& =0.34
\end{aligned}
$$

[R5] IF Risiko Bahan Baku TINGGI And Risiko Proses Pengolahan SEDANG And Risiko Sumber Daya Manusia SEDANG THEN tingkat risiko SEDANG

$\alpha$ Predikat $_{5}=\mu$ RBBTINGGI $\cap \mu$ RPPSEDANG $\cap$ $\mu$ RSDMSEDANG

$$
\begin{aligned}
& =\min [(0.65) ;(0.61) ;(0.11)] \\
& =0,11
\end{aligned}
$$

[R6] IF Risiko Bahan Baku TINGGI And Risiko Proses Pengolahan SEDANG And Risiko Sumber Daya Manusia TINGGI THEN tingkat risiko TINGGI

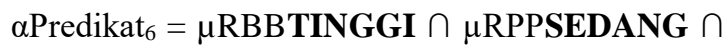
$\mu$ RSDMTINGGI

$$
\begin{aligned}
& =\min [(0.65) ;(0.61) ;(0.88)] \\
& =0.61
\end{aligned}
$$

[R7] IF Risiko Bahan Baku TINGGI And Risiko Proses Pengolahan TINGGI And Risiko Sumber Daya Manusia SEDANG THEN tingkat risiko TINGGI

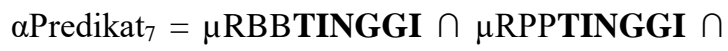
$\mu$ RSDMSEDANG

$$
\begin{aligned}
& =\min [(0.65) ;(0.38) ;(0.11)] \\
& =0.11
\end{aligned}
$$

[R8] IF Risiko Bahan Baku TINGGI And Risiko Proses Pengolahan TINGGI And Risiko Sumber Daya Manusia TINGGI THEN tingkat risiko TINGGI

$\alpha$ Predikat $_{27}=\mu$ RBBTINGGI $\cap \mu$ RPPTINGGI $\cap$ $\mu$ RSDMTINGGI

$$
\begin{aligned}
& =\min [(0.65) ;(0.38) ;(0.88)] \\
& =0.38
\end{aligned}
$$

Aplikasi fungsi setiap aturan, digunakan metode Max untuk melakukan komposisi antar semua aturan. Hasil dari verifikasi menggunakan MatLab dapat dilihat pada Gambar 5.

Hasil verifikasi output nilai risiko menggunakan aplikasi MatLab yaitu sebesar 423, artinya kategori nilai risiko yang diperoleh PG. Padjarakanyaitu tinggi. Oleh karena itu, dengan adanya software MatLab tersebut mempermudah dalam perhitungan defuzzyfikasi.

Setelah merumuskan setiap level pada struktur AHP, kemudian dilakukan pembobotan pada masing-masing kriteria 
pada setiap level oleh ketiga pakar. Selanjutnya dilakukan penggabungan pendapat dari masing-masing pakar yang telah memberikan pembobotan. Dari hasil penggabungan pendapat ini diolah kembali sehingga didapatkan dua model perhitungan horizontal dan pengolahan vertikal. Berikut ini hasil perhitungan pembobotan hirarki dapat dilihat pada Gambar 6.

Berdasarkan hasil perhitungan bobot formulasi strategi pengendalian risiko mutu, faktor/kriteria dengan bobot prioritas tertinggi yaitu Kualitas Bahan Baku $(0,388)$. Kualitas bahan baku yang baik maka akan mempengaruhi kualitas gula kristal putih yang dihasilkan. Aktor dengan bobot prioritas tertinggi yaitu Pekerja (0.258). Pekerja yang kompeten akan bekerja secara benar sehingga dalam proses on-farm dan off-farm dapat dilakukan dengan baik. Tujuan dengan bobot prioritas tertinggi yaitu Mengurangi Risiko Cacat Produk (0.323). Jika proses on-farm sampai off-farm dilakukan secara baik dan benar maka dapat mengurangi kecacatan produk yang dihasilkan. Alternatif yang dipilih adalah yang memiliki bobot prioritas tertinggi yaitu Pelatihan SDM (0.317). Pelatihan SDM dilakukan untuk menambah skill dan pengetahuan pekerja sehingga mampu bekerja dengan baik.

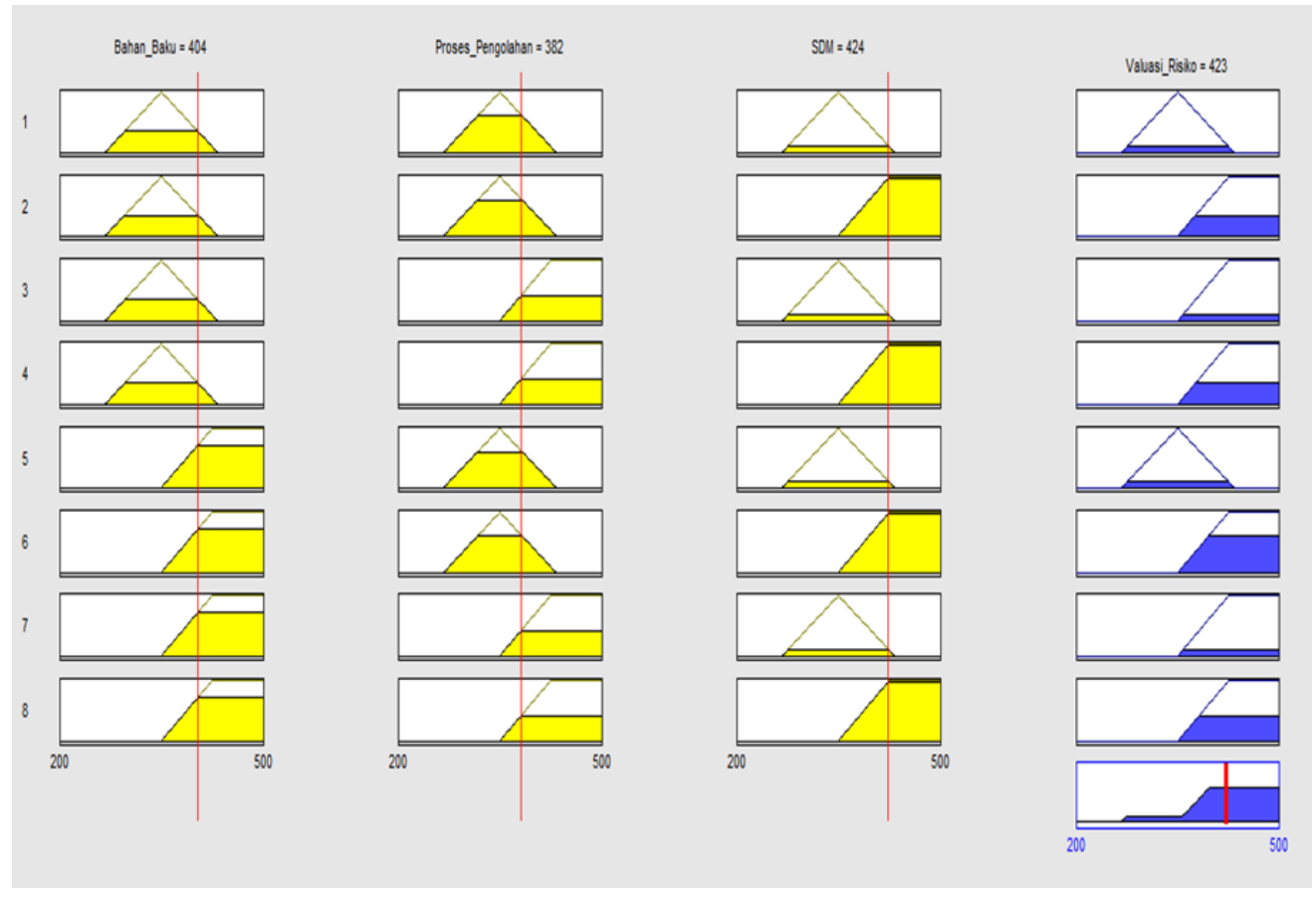

Gambar 5 Hasil daerah komposisi 


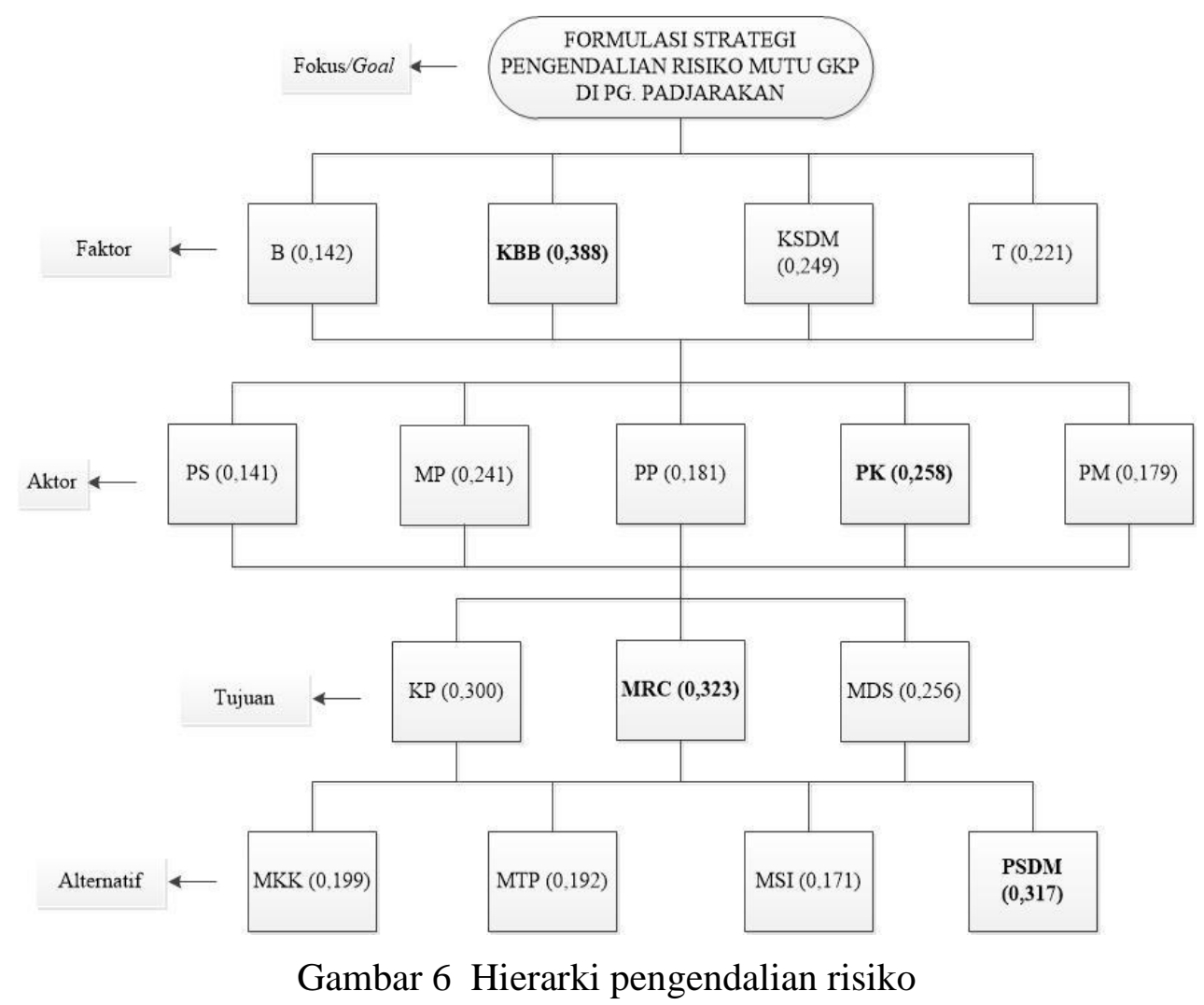

\section{KESIMPULAN}

Kesimpulan yang dapat diambil dari hasil dan pembahasan yaitu sebagai berikut : Faktor risiko yang mempengaruhi PG. Padjarakan meliputi risiko bahan baku, risiko proses pengolahan dan risiko sumber daya manusia. Berdasarkan hasil perhitungan diperoleh nilai risiko Bahan Baku sebesar 404, nilai risiko Proses Pengolahan sebesar 381.98 dan nilai risiko Sumber Daya Manusia sebesar 423.54. Keseluruhan untuk nilai agregasi ketiga Risiko diatas memperoleh nilai 423, sehingga tergolong faktor risiko tinggi. Berdasarkan perhitungan pakar, alternatif terpilih yaitu Pelatihan SDM dengan nilai bobot tertinggi (0.317). Pelatihan yang dilakukan nantinya mampu mengatasi dan meminimalisir munculnya risiko yang ada di PG. Padjarakan dalam segala bidang pekerjaan.

\section{DAFTAR PUSTAKA}

Alamsyah, B. D. 2013. Aplikasi Manajemen Risiko Pada Industri Kecil Nata De Coco (Studi Kasus Di Ud. Citra Mandiri Margo Mulyo Muktisari-Jember). Jember: Teknologi Hasil Pertanian Universitas Jember.

Darwin, P. 2013. Menikmati Gula Tanpa Rasa Takut. Yogyakarta: Sinar Ilmu. Dewan Gula Indonesia. 2009. Hasil Perhitungan Biaya Pokok Produksi (BPP) Gula Petani Tahun 2009. Jakarta: Dewan Gula Indonesia.

Kusumadewi, S. dan H. Purnomo. 2004. Aplikasi Logika Fuzzy untuk Pendukung Keputusan. Edisi 1. Yogyakarta: Graha Ilmu.

Kuswurj, R., 2009. Sugar Technology and Research: Kualitas Mutu Gula Kristal Putih. Institut Teknologi Surabaya,
Surabaya. 
http://www.risvank.com [26 Juli 2018].

Lahay, R. 2009. Pemuliaan Tanaman Tebu.

Medan: Departemen Budidaya Pertanian, Fakultas Pertanian, Universitas Sumatera Utara.

Mulyadi, 2005. Akuntansi Biaya. Edisi Kelima. Yogyakarta: UPPAMP YKPN Universitas Gajah Mada

Naba, A. 2009. Belajar Cepat Fuzzy Logic Menggunakan Matlab. Yogyakarta: ANDI.

Perkebunan Nusantara, PT. 2016. Pabrik Gula.http://ptpn11.co.id/page/pabrik -gula. [Diakses pada 15 Juli 2018].

Saaty, T.L. 1988. Multicriteria Decision Making: The Analytic Hierarchy Process. Pittsburgh: University of Pittsburgh, RWS Publication.

Sari, N.D.K. 2012. Analisis Pengendalian Persediaan Bahan Baku Tebu Dalam Pembuatan Gula Pasir Di Pabrik Gula Soedhono Kabupaten Ngawi. Skripsi. Surakarta: Fakultas Pertanian Universitas Sebelas Maret.

Sawit. 2004. Kajian Komparasi dari Perspektif Indonesia. Jakarta: Sekretariat Dewan Ketahanan Pangan.

Soekartawi. 2001. Pengantar Agroindustri. Jakarta: PT. Raja Grafindo Persada.

Sunaryo, T. 2009. Manajemen Risiko Finansial. Jakarta: Salemba Empat. 